\title{
O projeto MAMNBA: contexto político institucional, desdobramentos conceituais e técnicos
}

MAMNBA Project: political and institutional context, conceptual and technical developments.

hitps://doi.org/10.1590/1982-02672020v28d2e29

\section{MARCIA SANT'ANNA'}

https:/ / orcid.org/0000-0003-4162-9473

Universidade Federal da Bahia / Salvador, BA, Brasil

RESUMO: $O$ artigo aborda o projeto Mapeamento de Sítios e Monumentos Religiosos Negros da Bahia (MAMNBA) como um indicador importante de dois movimentos convergentes que tomam corpo a partir nos anos 1980 no Brasil: o da emergência do "patrimônio nacional" como um campo de luta política apropriado por movimento sociais negros de afirmação de direitos culturais e de quebra do monopólio luso-brasileiro nas representações da história do país; e o da ampliação da antiga noção de patrimônio histórico e artístico, com sua paulatina substituição pela noção de patrimônio cultural. Aborda, ainda, o modo como a Constituição Federal de 1988 recepcionou esses movimentos e como suas diretrizes relativas ao patrimônio afro-brasileiro foram absorvidas na política de preservação do patrimônio cultural, especialmente no âmbito federal. Tomando esta esfera do poder público como foco, o artigo trata também dos desdobramentos conceituais, metodológicos e práticos que a proteção e salvaguarda desse patrimônio produziu no âmbito do Instituto do Patrimônio Histórico e Artístico Nacional (lphan), a partir do tombamento de diversos terreiros de candomblé na Bahia e em outros estados do país. Por fim, o artigo aborda os conflitos e contradições que emergiram a partir da gestão e do dia a dia da preservação desses bens culturais, entre as concepções da área técnica do lphan sobre a sua conservação e a visão das comunidades de culto sobre o que é o seu patrimônio cultural e como este deve ser preservado nesses sítios.

PALAVRAS-CHAVE: Projeto MAMNBA. Patrimônio afro-brasileiro. Política de preservação.

\begin{abstract}
1. Graduada em Arquitetura e Urbanismo pela Universidade de Brasília (UnB), mestra e doutora em Arquitetura e Urbanismo pela Universidade Federal da Bahia (UFBA). Atualmente é professora adjunta da Faculdade de Arquitetura da Universidade Federal da Bahia e professora permanente do Programa de Pós-Graduação em Arquitetura e Urbanismo da mesma instituição. É ainda professora permanente do Mestrado Profissional em Conservação e Restauração de Monumentos e Núcleos Históricos da UFBA e professora colaboradora, desde 2010, do Mestrado Profissional em Preservação do Patrimônio (PEP-MP) do Instituto do Patrimônio Histórico e Artístico Nacional (Iphan). E-mail: <santanna.m@gmail.com>
\end{abstract}


ABSTRACT: The article approaches the Black Religious Monuments and Sites Mapping Project (MAMNBA) as an important indicator of two converging movements that take shape in the 1980s in Brazil. The first one is the emergence of the "national heritage" as a field of political struggle appropriated by black social movements that seek the affirmation of their cultural rights and the breaking of the Portuguese-Brazilian monopoly of the representations of the history of the country. The second one is the extension of the old concept of historical and artistic heritage until its gradual replacement by the notion of cultural heritage. It also addresses the way in which the Federal Constitution of 1988 welcomed these movements and how their guidelines regarding Afro-Brazilian heritage were absorbed in the policy of cultural heritage preservation, especially at the federal level. Taking this sphere of public power as a focus, the article also deals with the conceptual, methodological and practical developments that the protection and safeguarding of this particular cultural heritage has produced within the scope of the Institute of National Historic and Artistic Heritage (lphan), since the listing of several Terreiros de Candomblé in Bahia and in other states of the country as cultural heritage. Finally, the article addresses the conflicts and contradictions that emerged from the day-to-day management and preservation of these cultural properties between the conceptions of Iphan's technical staff on the conservation of these religious spaces and what the cult communities consider their cultural heritage and how it should be preserved in these sites.

KEYWORDS: MAMNBA Project. Afro-Brazilian Heritage. Preservation Policy. 


\section{INTRODUÇÃO}

antigo Curso de Especialização em Conservação e Restauração de Monumentos e Sítios Históricos (Cecre) correspondeu à quarta edição de uma iniciativa financiada pelo Programa de Cidades Históricas (PCH), em convênio com universidades brasileiras, voltada, naquele contexto de modernização e ampliação do aparato institucional de preservação do patrimônio dos anos 1970, para a formação e a capacitação de quadros técnicos dos organismos estaduais de preservação que vinham surgindo desde o final dos anos 1960. Antes desta edição, sediada pela Universidade Federal da Bahia (UFBA) em 1981, o curso havia sido realizado em São Paulo (1974), em Recife (1976) e em Belo Horizonte (1978). Contudo, foi em Salvador onde se fixou, se tornou de alcance internacional, com a admissão de estudantes provenientes da América Latina, e onde permanece até hoje como mestrado profissional. ${ }^{2} \bigcirc$ Cecre oferecia uma formação de ponta e contava com a presença de profissionais do campo da conservação e do restauro de renome internacional. $\bigcirc$ foco eram as edificações tombadas pelo poder público, pois, embora o curso abarcasse sítios históricos, a questão do patrimônio urbano era tocada apenas no que diz respeito ao entorno de monumentos e à história da formação e desenvolvimento das cidades onde se inserem. A discussão, à época já em curso no âmbito da antiga Fundação Nacional PróMemória, ${ }^{3}$ em torno do que Aloísio Magalhães chamava de "bens culturais", 4 assim como as experiências inovadoras de salvaguarda realizadas por projetos fomentados por esta fundação, tampouco constavam dos programas desses cursos. Os arquitetos, tanto os antigos quanto os novos, em formação, simplesmente passavam ao largo da revolução conceitual e da nova perspectiva que, já no final da década de 1970, começara a transformar o campo do patrimônio.

Esta breve digressão tem três objetivos. $\bigcirc$ primeiro é ressaltar alguns aspectos da prática institucional de preservação do patrimônio cultural, no albor da década de 1980, que ajudam a compreender as dificuldades enfrentadas pelo projeto Mapeamento Monumentos e Sítios Religiosos Negros da Bahia (MAMNBA), uma dessas experiências emblemáticas da Fundação Nacional Pró-Memória, na consecução de alguns de seus objetivos. São eles: a permanência dos arquitetos como os principais atores e interpretes do campo da preservação; a resiliência de uma concepção monumental e material do patrimônio na formação dos novos quadros; e o relativo isolamento dos arquitetos do lphan da discussão sobre a ampliação da noção de patrimônio que se desenvolveu na Fundação Nacional PróMemória ao longo dos anos 1980. O segundo objetivo é mostrar as discussões que o projeto MAMNBA incorporava e que contribuíram para alterar a concepção de patrimônio então ainda vigente, ressaltando também o seu caráter de campo de lutas
2. Mestrado Profissional em Conservação e Restauração de Monumentos e Núcleos Históricos (MP-CECRE) - ver informações em <https:// cecre.ufba.br/>.

3. A Fundação Nacional Pró-Memória foi criada em 1979 para atuar como o braço executivo da antiga Secretaria do Patrimônio Histórico e Artístico Nacional.

4. Cf. Magalhães (1985). 
e disputas sobre o que se concebe e se narra como nação e sociedade em cada momento histórico. Por fim, essa digressão tem também a intenção de ressaltar a diferença de postura dos arquitetos que, nos anos 1980, abraçaram a ampliação conceitual deflagrada pela Fundação Nacional Pró-Memória e buscaram se abrir e aprender com ela, em contraste com uma maioria de profissionais que a ignorou ou adotou uma postura de resistência e de pouca abertura a qualquer novo aprendizado.

Participar da equipe de implementação do projeto MAMNBA foi a minha primeira tarefa como especialista em conservação e restauração de monumentos. Devo registrar, portanto, o meu envolvimento pessoal e o enorme apreço que tenho por este projeto, pois, se o Cecre me deu a régua e o compasso inicial da conservação e do restauro, foi no projeto MAMNBA onde efetivamente aprendi o que é patrimônio, vislumbrei e compreendi sua dimensão política essencial. Nele tomei contato com o caráter multifacetado e pluridimensional da constituição de patrimônios e com a interdisciplinaridade que necessariamente deve estar envolvida na prática de salvaguarda. Posso afirmar, sem exagero, que a minha trajetória profissional foi marcada pelo que aprendi naquela oportunidade, assim como pelo convívio com antropólogos, sociólogos e historiadores neste e em outros projetos da Fundação Nacional Pró-Memória.

Uma vez explicitado o meu lugar de fala, completo esta breve introdução alertando que minhas próprias vivências e memórias como membro da equipe do projeto MAMNBA são parte das fontes primárias mobilizadas neste artigo. Outras fontes importantes foram os escritos do antropólogo Ordep Serra, que formulou este projeto juntamente com o arquiteto Orlando Ribeiro e o coordenou entre 1982 e 1987, e a entrevista que me concedeu em 3 de maio de 2019 sobre o contexto institucional e político no qual a iniciativa se desenvolveu e seus desdobramentos. As fontes bibliográficas que complementam esta análise dizem respeito à articulação fundamental do projeto MAMNBA às reivindicações dos movimentos sociais negros das décadas de 1970 e 80 e à emergência da ideia de patrimônio afro-brasileiro no contexto do processo de democratização do país.

\section{MOVIMENTOS NEGROS, REIVINDICAÇÕES HISTÓRICAS E EMERGÊNCIA DO PATRIMÔNIO AFRO-BRASILEIRO}

Estudiosos dos movimentos sociais e culturais negros apontam que, a partir dos anos 1920, quando surgem as primeiras lideranças e organizações que congregaram egressos da escravidão e seus descendentes, a reinvindicação de 
direitos relativos ao exercício pleno da cidadania, à integração do negro na sociedade e no mercado de trabalho se mantiveram como pautas essenciais e constantes, inclusive como forma de combate do racismo. Antônio Risério aponta que, ao longo do século XX, dois momentos podem ser considerados fundamentais nesta trajetória: o que se desenvolveu entre os anos 1920 e 30, marcado pela criação da Frente Negra Brasileira e pela explicitação de demandas relativas à integração dos negros na sociedade e no trabalho urbano assalariado; e o que se desenvolveu entre as décadas de 1970 e 80, quando essas demandas ganharam "extensão e radicalidade" sob a inspiração das lutas por direitos civis dos negros norte-americanos, do desenvolvimento de uma "consciência e sensibilidade antropológica" na academia brasileira e da redefinição da ideia de cidadania sob a égide da defesa das diferenças, das minorias e de uma sociedade pluralista. ${ }^{5}$

Este segundo momento foi também marcado pela criação do Movimento Negro Unificado (MNU) e pelo processo de redemocratização do país após cerca de 20 anos de ditadura militar. Se o comportamento da pequena burguesia, branca ou mestiça, foi tomado pela Frente Negra Brasileira como referência inicial, nesse momento tudo muda, passando a ser a ancestralidade africana a referência fundamental. Uma das primeiras expressões dessa troca de referências foi o novo Carnaval que surgiu na Bahia nos anos 1970, marcado pelos "blocos afros" e sua celebração da África Negra. ${ }^{\circ}$ Nos anos 1970 e 80 os movimentos sociais negros saíram do seu isolamento inicial com relação a outros setores da sociedade brasileira, para o que muito contribuíram as iniciativas governamentais de aproximação do Brasil com países africanos recém-independentes, como Angola, Moçambique e Guiné-Bissau, a abertura de cursos sobre cultura negra na academia e o apoio dado pela esquerda e pelo movimento estudantil ao próprio MNU.7

Em termos de reivindicações, contudo, esses dois momentos não diferem muito, pois mais educação e saúde, melhor habitação, melhores empregos e salários maiores permaneceram na pauta de reivindicações. Contudo, cabe ressaltar a emergência de uma reivindicação, se não nova, pelo menos mais bem explicitada nos anos 1980: a da "reavaliação do papel do negro na História do Brasil". ${ }^{8}$ Essa demanda começou a ser atendida, em termos legais e institucionais, nos anos 1980, com o surgimento e a afirmação da existência de um patrimônio afro-brasileiro deflagrada com a criação do Memorial Zumbi, em União dos Palmares, AL, e consolidada com os tombamentos da Serra da Barriga lou Quilombo dos Palmares), nessa mesma localidade, e do Terreiro da Casa Branca do Engenho Velho, na Bahia. Essas iniciativas vinculam-se à Fundação Nacional Pró-Memória e foram realizadas em articulação com lideranças religiosas e de movimentos sociais e culturais negros. Como será mais detalhado em seguida,
5. Risério (2007, p. 371-372).

6. Cf. Risério $(1981 ; 2007$, p. 373).

7. Risério (2007, p. 372-375).

8. De acordo com Risério (2007, p. 379), essa reivindicação consta da Carta de Princípios do MNU, de novembro de 1978. 
9. Revista do Patrimônio Histórico e Artístico Nacional, n. 25, 1997, intitulada Negro Brasileiro Negro.

10. Santos (1997, p. 5-9).

11. Ibid., p. 7-8.

12. Francisco (1997, p. 185-188).

13. Ibid., p. 190-195. dirigentes dessa fundação e membros do projeto MAMNBA participaram ativa e decisivamente dessas iniciativas. A luta pelo reconhecimento do lugar e da contribuição do negro na História do Brasil - luła que ainda continua - teve, assim, uma primeira vitória no começo da década de 1980. Com a promulgação dos artigos 215, 216 e 68, do Ato das Disposições Constitucionais Transitórias (ADCT) da Constituição Federal em 1988, e com a criação da Fundação Cultural Palmares, nesse mesmo ano, essa luta obteve importantes reforços legais.

Mas como o patrimônio se tornou um campo de afirmação política, cultural e social para os afro-brasileiros?

Em artigo publicado na primeira Revista do Patrimônio Histórico e Artístico Nacional dedicada ao papel do negro na formação cultural do Brasil, 9 o historiador Joel Rufino dos Santos aponta a dificuldade de se distinguir o patrimônio afro-brasileiro do patrimônio cultural do país num sentido amplo. ${ }^{10}$ Mostra, entretanto, que sempre houve uma rejeição por parte da sociedade "branca" de ser representada pelo negro, dentro ou fora do país, a despeito de Pelé e do samba serem vistos externamente como símbolos nacionais. Embora não tenha este objetivo, Joel Rufino registra, neste texto, um entendimento que, a meu ver, expressa muito bem a função do patrimônio na luta dos afro-brasileiros pelo reconhecimento do seu papel na construção da sociedade brasileira: a de uma categoria capaz de sinalizar para todos que os negros são produtores de bens culturais fundamentados na tradição, mas capazes de "se lançar no futuro" e de influenciar outras práticas e bens como fontes de civilização. Capazes, portanto, de "converter a energia simbólica, de que nos orgulhamos, na energia política necessária para diminuir as injustiças sociais que nos constrangem". "1

Dalmir Francisco, por sua vez, relaciona a reivindicação de um patrimônio afro-brasileiro à luta política pela superação da subalternização e aos esforços no sentido de um exercício pleno da cidadania políica e cultural que foram empreendidos pelas comunidades religiosas e culturais afro-brasileiras e suas instituições comunitárias. ${ }^{12}$ Francisco ressalta que a luta pela identidade étnico-cultural afrobrasileira foi "inspirada, orientada e dirigida pela tradição [...] localizada nos territórios das instituições religiosas ou laicas", bem como pelas ações contra um racismo legitimador de desigualdades sociais e econômicas. $\bigcirc$ autor aponta que a tradição que fundamentou a luta pela identidade étnico-cultural dos afrodescendentes somente pôde avançar com o restabelecimento do jogo democrático nos anos 1980, a despeito de não ter conseguido "transformar seus princípios, valores étnicos e morais em proposições ou orientações políticas e sociopolíticas de caráter transformador para o conjunto da população negra e afro-brasileira". ${ }^{13}$ 
A trajetória das demandas e do próprio movimento social negro no Brasil mostra, além de uma longa permanência de reivindicações não atendidas, que o patrimônio cultural, ainda que tardiamente, surgiu nos anos 1980 como um campo importante para a afirmação do papel central dos afro-brasileiros na história e na formação cultural do país. Surgiu, ainda, como um instrumento de afirmação de uma identidade de cunho étnico e cultural, com impactos positivos, ainda que limitados, nas lutas por espaço e representação na sociedade. Nesse processo, a Fundação Nacional Pró-Memória e o projeto MAMNBA desempenharam um papel fundamental.

\section{O PROJETO MAMNBA E SEUS DESDOBRAMENTOS}

$\bigcirc$ projeto MAMNBA pertence ao conjunto de ações que, a partir da criação do Centro Nacional de Referências Culturais (CNRC) e, em seguida, da Fundação Nacional Pró-Memória (FNPM), reconfiguraram, ampliaram e renovaram o campo da preservação do patrimônio no Brasil. Como já descrito por vários autores, o final dos anos 1970 correspondem a uma reaproximação, ${ }^{14}$ abundante e profícua, de antropólogos, sociólogos, historiadores, dentre outros profissionais, do campo do patrimônio, o que relativizou, durante os anos 1980, o domínio dos arquitetos sobre os processos de constituição de patrimônios no Brasil.

Como braço executivo da antiga Secretaria do Patrimônio Histórico e Artístico Nacional (Sphan), a FNPM não possuía uma estrutura rígida, atuando por meio de projetos vinculados a questões da cultura e a áreas de conhecimento. Dentre estes, cabe destacar o Projeto Etnias e Sociedade Nacional, desenvolvido a partir de 1980 e coordenado nacionalmente pelo antropólogo Olympio Serra. objetivo deste projeto era, explicitamente, romper com a "fixação eurocêntrica" da política cultural brasileira por meio do resgate das memórias indígenas e afrobrasileiras. ${ }^{15}$ Este resgate não foi iniciado isoladamente pela FNPM, mas mediante a mobilização de lideranças e instituições engajadas nessas lutas, o que, no que diz respeito aos afro-brasileiros, expressou-se, inicialmente, na criação do Memorial Zumbi, cujo conselho, composto por organizações de combate ao racismo, de defesa dos direitos humanos e por líderes de comunidades religiosas e culturais, passou a ser presidido pelo próprio Olympio Serra. ${ }^{16}$ Cabe ressaltar que o MNU e outras organizações sociais negras, até então, não haviam ainda incluído o patrimônio em sua pauta de reivindicações, movimento que foi incitado pelas iniciativas dos antropólogos então reunidos na FNPM. ${ }^{17}$
14. Reaproximação porque, em 1937, na institucionalização da proteção ao patrimônio no Brasil, antropólogos, sociólogos e historiadores exerceram também um papel fundamental na constituição e delimitação deste campo; cf. Fonseca (1997); Chuva (2017).

15. Serra (2011, p. 38).

16. Ibid.

17. Esta informação foi obtida com Ordep Serra, coordenador do Projeto MAMNBA em entrevista concedida em 3 de maio de 2019. 
18. Serra (op. cit., p. 38-39).

19. Cf. nota 17.

20. As ações-exemplo eram destinadas a apontar caminhos em favor da preservação de bens culturais num sentido amplo. Falcão (1985, p. 19-20).

21. Serra (2011, p. 39).
O projeto MAMNBA é fruto direto desse contexto, tendo sido formulado já em 1981, portanto, logo após a criação do Memorial Zumbi. ${ }^{18}$ Segundo Ordep Serra, ${ }^{19}$ a ideia surgiu de uma pergunta feita por Olympio Serra em meio a essa cruzada inicial pelo reconhecimento do patrimônio afro-brasileiro: "Que tal tombar o Terreiro do Gantois?" Dessa pergunta, que dialoga diretamente com a noção de "ação-exemplo" criada por Aloísio Magalhães, ${ }^{20}$ surgiv a proposta de realização de um inventário dos monumentos e sítios vinculados aos cultos de matriz africana na Bahia que pudesse amparar a implementação de uma política consistente de reconhecimento e proteção desse patrimônio cultural.

E assim foi feito a partir da celebração de um convênio entre a FNPM, o antigo Órgão Central de Planejamento da Prefeitura Municipal de Salvador (Oceplan/PMS) e a Fundação Cultural do Estado da Bahia. As noções de monumentos e de sítios religiosos negros abarcavam templos, sítios naturais consagrados, hortos e obras de arte sacra, operando-se, portanto, com uma concepção bem mais ampla que a de monumento histórico, então ainda umbilicalmente ligada à arquitetura originária de povos europeus. Embora indicasse no seu fítulo a intenção de inventariar o estado da Bahia, desde o início e, certamente, em consequência da parceria firmada com a Prefeitura de Salvador, o projeto se restringiu à área desse município. Além disso, em vez de um inventário que seguisse os modelos internacionais já firmados naquela época, optou-se por um "mapeamento" voltado para quantificar, localizar e obter informações básicas - como nome do dirigente, nação e calendário de funcionamento - sobre os centros de culto afrobrasileiros existentes em Salvador. Esse trabalho foi feito a partir do levantamento e do cruzamento de dados existentes na Fundação Baiana dos Cultos Afro-brasileiros (Febacab), na Secretaria de Indústria Comércio do Estado da Bahia, na Fundação Cultural do Estado da Bahia e nos registros da antiga Delegacia de Jogos e Costumes, da Secretaria de Estado de Segurança Pública, que constituem testemunhos do período em que os terreiros de candomblé, para funcionar "legalmente", precisavam de autorização expressa dessa repartição pública. Sempre que surgia alguma contradição ou discrepância entre esses dados, realizava-se uma verificação in loco.

Além desse mapeamento geral, que indicou a existência de cerca de 2.000 terreiros em Salvador, o projeto MAMNBA tinha como parte da sua proposta a realização de estudos de caso, voltados, mais especificamente, para espaços religiosos afro-brasileiros em situação crítica ou de risco. ${ }^{21}$ Com este objetivo, foram selecionados: o Parque de São Bartolomeu, enorme área verde no subúrbio da cidade que foi objeto de elaboração de um plano de preservação não executado; - Terreiro da Casa Branca do Engenho Velho, com a realização de estudos para a instrução de processo de tombamento; e os terreiros do Axé Opô Afoniá, do Gantois, 
Ipatitió Gallo e Bogum, então sob ameaça de invasão e de perda de privacidade devido à intensa e irregular ocupação do solo em suas imediações, com estudos para a criação de Áreas de Proteção Cultural e Paisagística 22 no âmbito municipal, numa iniciativa que também incluiu o conjunto da Casa Branca. Dentre essas ações, a que, sem dúvida, mais funcionou como "ação-exemplo" nos moldes aloisianos, teve consequências importantes e mais contribuiu para os objetivos do projeto MAMNBA foi a do tombamento do Terreiro da Casa Branca do Engenho Velho.

Este processo já foi descrito em detalhes por Ordep Serra (201 1), tanto no que toca à sua instrução quanto à luta travada pela equipe do projeto MAMNBA para convencer os técnicos da antiga Diretoria de Tombamento e Conservação da Sphan, localizada no Rio de Janeiro, sobre a importância e a pertinência dessa iniciativa. $\bigcirc$ antropólogo Gilberto Velho (201 1), que foi relator do processo no Conselho Consultivo do Patrimônio Cultural, também descreveu detalhadamente as discussões e as posturas desse colegiado e da presidência do sistema Sphan/FNPM sobre essa proposta. Caberia, contudo, ressaltar o seu caráter de ação que inaugura o reconhecimento e a consolidação da noção de patrimônio afro-brasileiro no país. É importante também enfatizar que este tombamento deflagrou, na Bahia e no plano nacional, um verdadeiro movimento de mobilização social contra as ameaças de expulsão e destruição que pesavam sobre o Terreiro da Casa Branca, do qual participaram, além da comunidade de culto e da equipe do projeto MAMNBA, importantes lideranças religiosas afrobrasileiras e católicas, organizações antirracistas e de defesa de direitos civis, intelectuais, artistas e políticos baianos. $\bigcirc$ processo de tombamento aglutinou, assim, importantes forças e segmentos da sociedade, o que tornou esse terreiro um símbolo da luta pelo reconhecimento do lugar dos egressos da escravidão e de seus descendentes na construção da história e da sociedade brasileira.

Como já mencionado, o reconhecimento da importância histórica da vida, do trabalho, das lutas e da contribuição cultural e civilizatória dos afro-brasileiros na formação do país é uma reivindicação antiga dos movimentos sociais negros, que remonta, pelo menos, aos anos 1920. As discussões em torno da possibilidade de tombar o Terreiro da Casa Branca e, principalmente, dos valores que poderiam ser atribuídos a esse sítio, às suas edificações e obras de arte sacra dão uma boa medida, de um lado, do fechamento e da impermeabilidade do Iphan, naquele momento, a tudo que divergisse de uma noção de patrimônio assentada na arte e na arquitetura luso-brasileira e, de outro, da total falta de conhecimento, por parte dos servidores da instituição, sobre um universo cultural que sempre esteve presente no país, mas sobre o qual se lançava, então, uma visão claramente preconceituosa. A posição institucional à época pode ser assim resumida: o tombamento seria um instrumento que não se adequaria a esses sítios religiosos porque neles sequer existiria uma arquitetura ou
22. A Lei Municipal $n^{\circ} 3.289$, de 1983, criou as Áreas de Proteção Cultural e Paisagística com vistas à proteção como patrimônio de áreas consideradas importantes para a identidade da cidade. 
objetos de valor artístico, bem como nada que permitisse articulá-los à arte e à história do Brasil. No máximo, seria possível reconhecer nesse conjunto um valor etnográfico, relativo ao seu caráter diferenciado e exótico. $\bigcirc$ conflito em torno do tombamento do Terreiro da Casa Branca tornou-se, assim, dentro do Iphan, uma disputa pela narrativa histórica do país e, por isso, seus proponentes e defensores jamais abriram mão da reinvindicação de que este bem cultural, uma vez tombado, fosse também inscrito no Livro do Tombo Histórico e não somente no Livro do Tombo Arqueológico Etnográfico e Paisagístico, como aventou-se num momento dessa discussão.

Embora tenha sido claramente uma ação política, o processo de tombamento do Terreiro da Casa Branca foi também uma iniciativa inovadora em termos técnicos, podendo ser apontada como pioneira no cumprimento de um princípio que, hoje em dia, se torna cada vez mais basilar no processo de constituição e conservação de patrimônios no Brasil, ou seja, o da participação social. É certo que as equipes dos projetos Etnias e Sociedade Nacional e MAMNBA propunham esse tombamento como uma ação cultural e política estratégica. Contudo, a decisão de solicitar e iniciar o processo foi da Sociedade Beneficente e Recreativa São Jorge do Engenho Velho, representante civil da comunidade da Casa Branca. Essa decisão foi tomada de modo consciente, informado, com pleno conhecimento das consequências desse ato administrativo e após muitos meses de reflexão, durante os quais a busca por outras soluções para o problema fundiário que promovia a expulsão da comunidade foi também constante. ${ }^{23} \bigcirc$ caráter participativo desse processo de tombamento também pode ser atestado no modo como a sua instrução foi realizada, uma vez que, além de acompanharem a equipe do projeto MAMNBA nos levantamentos fotográficos e cadastrais necessários, membros do terreiro atuaram diretamente na produção de conhecimento sobre o sítio, no levantamento de sua história, na identificação do que era importante preservar e na definição das bases sobre as quais essa preservação deveria ocorrer. Em suma, participaram como sujeitos e intérpretes da constituição da Casa Branca como patrimônio, inclusive no que toca à elaboração de um plano de preservação para o terreiro, que, pioneiramente, foi incluído como parte da instrução do processo de tombamento.

Ainda como ação política, o tombamento do Terreiro da Casa Branca foi bem-sucedido no aspecto da promoção, já que deu a conhecer ao grande público um universo religioso e cultural que, a despeito de ter sempre estado presente nas cidades brasileiras, não era efetivamente visto. Na realidade, quando posto na ribalta pelos órgãos de segurança pública, esse universo era sempre descrito de maneira negativa, racista e preconceituosa, como ilustram os vários "museus" denominados de "magia negra" ou de "feitiçaria", criados para associação dessas 
práticas religiosas e culturais a patologias psiquiátricas e ao crime. ${ }^{24} \bigcirc$ tombamento da Casa Branca favoreceu outro olhar sobre esse universo e outra ideia de patrimônio. Por essa razão, e diante da eficácia dessa ação-exemplo, cabe indagar por que houve um hiato de 15 anos entre esse e o subsequente tombamento de um terreiro de candomblé, o do Axé Opô Afoniá, também localizado em Salvador.

Não somente o Iphan tinha dúvidas ou restrições quanto ao tombamento desses bens culturais, mas também as comunidades de culto e os intelectuais a elas vinculados as tinham. Como informa Ordep Serra, ${ }^{25}$ antropólogos e pesquisadores desse universo religioso, como Vivaldo da Costa Lima, Júlio Braga e Juana Elbein dos Santos, por exemplo, posicionaram-se, inicialmente, contrários a esse tipo de iniciativa, que viam, à época, como uma possibilidade de interferência indevida nos terreiros de candomblé. Em grande parte, este tipo de postura explica a negativa inicial de Mãe Stella de Oxóssi, ialorixá do Axé Opô Afonjá, ${ }^{26}$ à proposta de tombamento desse terreiro que the foi feita pela equipe do projeto MAMNBA ainda em 1982. Na realidade, o tombamento da Casa Branca funcionou como um teste para as demais comunidades de culto sobre a eficácia e a adequação do tombamento às realidades e especificidades dos terreiros, daí o longo intervalo até que uma nova solicitação de tombamento surgisse. Na revisão dessa postura inicial, pesaram, sem dúvida, os benefícios auferidos pela Casa Branca com a desapropriação do terreno que ocupa, incluída a área que havia perdido para um posto de gasolina, ${ }^{27}$ bem como com as obras de conservação de santuários e do templo principal do terreiro, realizadas pelo Instituto do Patrimônio Artístico e Cultural da Bahia (lpac), e com os melhoramentos gerais em todo o sítio, realizados, nos anos 1990, pela Prefeitura de Salvador, o que contemplou contenção de trechos da encosta, pavimentação, reparos gerais em todos os santuários, fechamento do terreno com gradil artisticamente trabalhado e tratamento de plantas e árvores sagradas. Esses benefícios, assim como o prestígio nacional adquirido por esse terreiro como patrimônio cultural, ajudaram a mudar a percepção das comunidades de culto sobre o tombamento.

A comunidade do Terreiro da Casa Branca decidiu correr o risco de aceitar o tombamento porque, de fato, não tinha alternativa. Entretanto, vale ressaltar que a mobilização realizada por Olympio Serra em torno da ideia de reconfigurar o patrimônio protegido pelo Estado, mediante a inclusão das memórias negras e indígenas, também teve peso nessa decisão, já que membros desse terreiro participaram da mobilização que resultou na criação do Memorial Zumbi dos Palmares. ${ }^{28}$ Assim, é possivivel afirmar que essas lideranças, além de buscar no tombamento uma solução para fazer face às ameaças de expulsão que estavam enfrentando, participavam
24. Serra (2014, p. 97-129).

25. Informação prestada em entrevista concedida em 3 de maio de 2019.

26. Mãe Stela de Oxossi faleceu em dezembro de 2018.

27. Esta área foi posteriormente reconfigurada como Praça de Oxum, mediante projeto do arquiteto Oscar Niemeyer.

28. Serra (2011, p. 38). 
29. Cf. Sant'Anna (2011).

30. Cf. Chuva (2017).

31. Mapeamento dos terreiros... (2008, p. 16). ativamente das lutas pelo reconhecimento do lugar do negro na sociedade e na história do país. Foram, assim, inegavelmente pioneiros e, concretamente, abriram caminho para a ampliação da noção de patrimônio no Brasil. ${ }^{29}$

O projeto MAMNBA, por meio do tombamento da Casa Branca, "forçou a porta" da área técnica do Iphan e da própria cultura institucional de conservação e gestão do patrimônio edificado. Ainda que de modo limitado em termos de uma transformação total dessa cultura, iniciativas como essa, nos anos 1980, obrigaram a instituição a lidar com novos universos culturais e, portanto, como aponta Marcia Chuva, com novos problemas, novas abordagens e novos objetos. ${ }^{30}$ Mesmo que vagarosamente, o Iphan foi levado a desenvolver expertises e buscar recursos humanos para lidar com todas essas novidades. $O$ projeto foi ainda um ponto de partida na produção de conhecimento sobre o patrimônio religioso negro, sobre sua situação fundiária e inserção no contexto urbano, o que referenciou importantes pesquisas, como o Mapeamento dos Terreiros de Salvador, realizado entre 2006 e 2007 pela Prefeitura de Salvador e Centro de Estudos Afro-Orientais da Universidade Federal da Bahia, quando 1.410 centros de cultos afro-brasileiros foram contabilizados. ${ }^{31}$ Em relação aos números dos anos 1980, esse mapeamento mais recente registrou a diminuição no número total de terreiros em Salvador como uma decorrência do avanço das religiões neopentecostais.

Mesmo após o seu encerramento, membros da equipe do projeto MAMNBA permaneceram dedicados à causa do patrimônio afro-brasileiro. Nesse sentido, essa iniciativa pode ser também definida como uma ação política engajada que desdobrou-se no apoio à solução de problemas de diversas comunidades de culto da Bahia, tanto por meio da mediação de conflitos com o poder público quanto mediante o apoio à instrução de processos de tombamento e registro, à medida que essas demandas foram crescendo na esteira da experiência bem-sucedida do Terreiro da Casa Branca. $O$ projeto MAMNBA, em suma, ajudou a mudar a mentalidade do Iphan sobre o patrimônio cultural a ser protegido e obrigou a instituição a construir novas formas de lidar e gerir bens pertencentes a universos culturais não consagrados pelo campo da preservação do patrimônio.

\section{O PATRIMÔNIO AFRO-BRASILEIRO HOJE E OS DESAFIOS DA SUA GESTÃO}

Os sucessos do projeto MAMNBA, entretanto, nem de longe superaram os desafios que o Iphan e os demais organismos públicos de preservação ainda têm pela frente com relação ao reconhecimento e à valorização do patrimônio afro-brasileiro. Em várias oportunidades, tem sido ressaltada a necessidade de ampliação da ação 
de identificação de sítios religiosos afro-brasileiros que constituem referências culturais no território nacional como base para a elaboração de uma política específica de reconhecimento, proteção e salvaguarda adequada à importância desse patrimônio. ${ }^{32}$ Um breve exame da lista atual de bens culturais tombados ou registrados pelo Iphan mostra, claramente, o modo como o universo cultural afro-brasileiro ainda se encontra representado de modo insuficiente. Como aponta Guran, de um total de 1.241 bens tombados até 2017, apenas 13 the são diretamente associados. ${ }^{33}$ Outros 13 bens culturais pertencentes a esse universo estão, por sua vez, registrados como patrimônio cultural do Brasil. ${ }^{34}$ É muito pouco, especialmente se consideramos, como bem observou Joel Rufino dos Santos, que o patrimônio afro-brasileiro é tudo "o que em nós não é pose ou imitação" ou, ainda, tudo o que diz respeito ao "conjunto de bens físicos e simbólicos que nos individualiza [...]" com relação a outros povos. ${ }^{35}$

Os desafios em termos de identificação, seleção e reconhecimento desses bens culturais são, portanto, de grande monta, mas não são menores do que aqueles relacionados à sua gestão cotidiana ou, mais genericamente, à sua conservação. Como observou o antropólogo Gilberto Velho no parecer que compõe o processo de tombamento do Terreiro da Casa Branca, ${ }^{36}$ o Iphan necessitaria adotar nesses casos uma postura flexível e compreender que o sentido último desses tombamentos é garantir a continuidade dessas expressões culturais e religiosas nos lugares que ocupam. Embora clara, os técnicos do lphan demoraram a compreender e incorporar essa postura, muitas vezes, abordando as edificações dos terreiros tombados com rigores estilísticos inadequados, sem atentar para a sua natureza de espaços sagrados que se adaptam continuamente às injunções do culto, aos desígnios das divindades que neles são cultuadas e, principalmente, a uma específica noção do que é fundamental e necessário preservar no que toca à dimensão material desses bens.

No âmbito do Programa de Pós-Graduação em Arquitetura e Urbanismo da UFBA, pesquisa recente mostra como os terreiros de candomblé possuem uma dinâmica própria de preservação dos aspectos materiais do seu patrimônio. ${ }^{37}$ Uma dinâmica que não busca a permanência geral e indiscriminada de objetos e elementos construídos, mas que se volta para o que é concebido como essencial à expressão das cosmovisões dessas comunidades e para tudo que produz, potencializa e transmite axé. $\bigcirc$ axé é a "força que assegura a existência dinâmica, que permite o acontecer e o devir" e que é contida e transmitida por certos materiais e substâncias, como explica Juana Elbein dos Santos. ${ }^{38}$ Denis Matos aponta que esta força é fundamental para o entendimento da prática de preservação que os terreiros realizam, já que para a manutenção e potencialização do axé, certas matérias precisam ser substituídas, transformadas e entregues à entropia do tempo - que, no candomblé, é uma divindade - mediante sua restituição à natureza. ${ }^{39}$ Os aspectos materiais que
32. Cf. Sant'Anna (2011).

33. Guran (2017, p. 221).

34. Considerando-se, neste número, o registro do Bembé do Mercado de Santo Amaro da Purificação, Bahia, realizado em 2019.

35. Santos (1997, p. 5).

36. Ata da $108^{\mathrm{a}}$ reunião do Conselho Consultivo do Patrimônio Histórico e Artístico Nacional, em 31 de maio de 1984.

37. Cf. Matos (2019). Esta pesquisa recebeu o Prêmio de Dissertação da Associação Nacional de Pesquisa e Pós-Graduação em Arquitetura e Urbanismo (Anparq) de 2018.

38. Santos (1983, p. 39-43). 39. Cf. Matos (2019). 
40. Entre outros, no âmbito do Programa de Pós-Graduação em Arquitetura e Urbanismo da UFBA, com estudos já publicados, Fábio Macêdo Velame (2019) e o já mencionado Denis Alex Barboza de Matos. fortalecem e potencializam o axé se expressam em certos elementos dos templos, determinados objetos rituais e espécimes vegetais cuja preservação se torna, assim, fundamental, pois carregam significados, sentidos e propósitos específicos vinculados à ancestralidade, às relações de parentesco e às trocas entre o mundo dos vivos e o dos deuses (ou seja, na cultura ioruba, entre o Orun e o Aiyê). Este deve ser então o foco da conservação da dimensão material desses bens culturais - foco que raramente é de conhecimento prévio dos técnicos das instituições de preservação. Assim, o processo de conservação deve ser necessariamente participativo e guiado pelas lideranças religiosas dos espaços protegidos.

A despeito de iniciativas importantes do Iphan, como a criação do Grupo Interdepartamental para Preservação do Patrimônio Cultural de Terreiros (GTIT), que desenvolveu, em parceria com a UFBA, um curso voltado para comunidades de culto e técnicos dos organismos de preservação, com vistas à discussão e elaboração de planos de preservação e gestão para terreiros tombados no estado da Bahia, muito pouco se avançou institucionalmente no sentido da ampliação e difusão do conhecimento sobre o patrimônio afro-brasileiro e sobre como lidar com ele. Exceto em setores específicos, como o Departamento do Patrimônio Imaterial, a instituição, no seu conjunto, ainda não está devidamente preparada para recepcionar e gerir adequadamente esses bens culturais, especialmente no que toca à sua dimensão material fundamental. De certa forma, é possível dizer que a instituição ainda necessita investir na produção de um conhecimento mais fino e aprofundado sobre esse universo cultural, o que nos leva a pensar se o projeto MAMNBA não deveria ter se transformado numa ação de âmbito nacional e caráter permanente.

A responsabilidade sobre esse estado de coisas não é, contudo, somente do Iphan. As comunidades de terreiros e os intelectuais e acadêmicos a elas vinculados pouco se dedicaram a pensar sistematicamente sobre os terreiros como patrimônios culturais do Brasil. Se, de um lado, não mais receiam que o tombamento restrinja ou impeça as dinâmicas dos cultos e vêm este instrumento como um modo de acesso a recursos públicos, por outro, pouco têm se dedicado a refletir sobre o sentido da patrimonialização desses sítios e sobre os compromissos de preservação que daí decorrem. Mas há esperança, pois, alguns experientes e jovens pesquisadores que são membros de comunidades de terreiros, em boa hora, estão se dedicando, no âmbito de programas de pós-graduação, à tarefa de refletir sobre o patrimônio afro-brasileiro e sua preservação. ${ }^{40} \bigcirc$ próprio Iphan, no Mestrado Profissional em Preservação do Patrimônio Cultural (PEP-MP), vem incentivando estudos dessa natureza e não há dúvida de que, cada vez mais, parcerias entre instituições de preservação e universidades são necessárias para que espaços de debate e tempos de estudo e reflexão possam ser criados em torno de discussões 
e questões fundamentais para a prática institucional de preservação do patrimônio, - em suma, para que essa prática possa se dar e se desenvolver em níveis de excelência, possibilitando que o patrimônio cultural reconhecido pelo Estado desempenhe plenamente sua função social e política como instrumento para um amplo exercício da cidadania, para o combate aos preconceitos sociais e raciais, para a inclusão de todos na história e na produção cultural do país e para a diminuição das distâncias e desigualdades sociais. 


\section{REFERÊNCIAS}

LIVROS, ARTIGOS E TESES

CHUVA, Marcia. Os arquitetos da memória: sociogênese das práticas de preservação do patrimônio cultural no Brasil (anos 1930-1940). Rio de Janeiro: UFRJ, 2009.

CHUVA, Marcia. Possíveis narrativas sobre duas décadas de patrimônio: de 1982 a 2002. Revista do Patrimônio Histórico e Artístico Nacional, n. 35, 2017, p. 79-103.

FALCÃO, Joaquim. A política cultural de Aloísio Magalhães. In: MAGALHÃES, A. E Triunfo? A questão dos bens culturais no Brasil. Rio de Janeiro: Nova Fronteira; Brasília: Fundação Nacional Pró-Memória, 1985, p. 19-20.

FONSECA, Maria Cecília Londres. O patrimônio em processo: trajetória da política federal de preservação no Brasil. Rio de Janeiro: Editora UFRJ: IPHAN, 1997.

FRANCISCO, Dalmir. Negro, Etnia, Cultura e Democracia. Revista do Patrimônio Histórico e Artístico Nacional, n. 25, 1997, p. 185-197.

MAGAlHÃES, A. E Triunfo? A questão dos bens culturais no Brasil. Rio de Janeiro: Nova Fronteira; Brasília: Fundação Nacional Pró-Memória, 1985.

MAPEAMENTO dos Terreiros de Salvador. Jocélio Teles dos Santos (coord.). Salvador: UFBA/ Centro de Estudos Afro-Orientais, 2008.

MATOS, Denis Alex Barboza de. A casa do Velbo: o significado da matéria no candomblé. Salvador: EDUFBA, 2019.

RISÉRIO, Antônio. Carnaval Ixejá: notas sobre afoxés e blocos do novo carnaval afro-baiano. Salvador: Currupio, 1981.

RISÉRIO, Antônio. A utopia brasileira e os movimentos negros. São Paulo: 34, 2007.

SANT'ANNA, Marcia. O tombamento de terreiros de candomblé no âmbito do Iphan: critérios de seleção e de intervenção. In: AMORIM, Carlos et al. O patrimônio cultural dos templos afro-brasileiros. Salvador: Oiti, 2011, p. 27-33. 
SANTOS, Joel Rufino dos. Culturas Negras, Civilização Brasileira. Revista do Patrimônio Histórico e Artístico Nacional, n. 25, 1997, p. 5-9.

SANTOS, Juana Elbein dos. Os Nàgô e a Morte: Pàde, Àsèsè e o Culto Égun na Bahia. Petrópolis: Vozes, 1986.

SERRA, Ordep. O tombamento do Terreiro da Casa Branca do Engenho Velho - Ilê Axé Iyá Nassô Oká. In: AMORIM, Carlos et al. O patrimônio cultural dos templos afro-brasileiros. Salvador: Oiti, 2011, p. 37-51.

SERRA, Ordep. Os olhos negros do Brasil. Salvador: EDUFBA: PPG-AU/UFBA, 2014.

VELAME, Fábio Macêdo. Arquiteturas da Ancestralidade Afro-brasileira; o Omo Ilê Agboulá - um templo de culto aos Egum no Brasil. Salvador: EDUFBA: PPG-AU/UFBA, 2019.

VELHO, Gilberto. Patrimônio, negociação e conflito. In: AMORIM, Carlos et al. O patrimônio cultural dos templos afro-brasileiros. Salvador: Oiti, 2011, p. 53-65.

VELHO, Gilberto. Antropologia e Patrimônio Cultural. Revista do Patrimônio Histórico e Artístico Nacional, n. 20, 1984, p. 37-39.

Artigo apresentado em 13/12/2019. Aprovado em 23/04/2020.

\section{(cc) BY}

All the contents of this journal, except where otherwise noted, is licensed under a Creative Commons Attribution License 